adjustment for sociodemographic characteristics, behavioural risk factors and health condition of individuals. But, the association between unemployment and poor self-rated health was not modified by neighbourhood socioeconomic indicators.

Conclusion Results confirm the association between unemployment and poor self rated health, regardless the personal or contextual characteristics studied here. Similarly, they show a clear independent association between self rated health and neighbourhood context. But, they do not show that the neighbourhood contexts investigated modify the associations between unemployment and poor self rated health.

\section{SP6-19 SERUM CONCENTRATION OF HCH, DDT AND METABOLITES IN ADOLESCENTS EXPOSED TO ORGANOCHLORINE PESTICIDE RESIDUES IN BRAZIL}

doi:10.1136/jech.2011.142976p.90

R Guimarães, ${ }^{*}$ I Braga, A Vianna, C Asmus. Federal University of Rio de Janeiro, Institute of Studies in Public Health, Rio de Janeiro, Brazil

Objective To evaluate the concentration of biomarkers of exposure to residues of organochlorine pesticides in adolescents in Rio de Janeiro, Brazil

Methods We obtained laboratory results of serum concentrations of the isomers of $\mathrm{HCH}$ and DDT metabolites from the data collection from medical records at a local health unit from a previous screening.

Results We observed concentrations were considered well above the tolerance limits allowed. The distribution shows typical asymmetrical pattern, because of the presence of individuals with concentrations outliers distribution. Deserve special attention from the $\mathrm{HCH}$ congeners, the p,p'DDT and p,p'DDE; whose serum concentration mean and median are much higher than the level of tolerance permitted. Concentration obtained were from a $\mathrm{HCH}$ (115.81 Mean \pm SD 1438.529), b HCH (1616266 Mean \pm SD 135.15), g HCH (Mean \pm 5373.357 SD 447.66), p, p'DDE (Mean $94.92 \pm 884979$ SD), p, p 'DDD (5:23 Mean \pm 43350 SD), o, p 'DDT (3596 Mean $1.82 \pm \mathrm{SD}$ ) and p, p' DDT (45.61 Mean \pm SD 464389). In measuring the correlation between different types of organochlorine compounds evaluated, it is observed that the majority has mayor correlation $(r=1.000)$, or nearly so, with great statistical significance $(p<0.0001)$.

Conclusion There is needing for monitoring and periodic evaluation of health of this population, considering that the blood is altered especially at this critical period of development.

\section{SP6-20 OCCUPATIONAL HEALTH RISKS: RELIABILITY TEST FROM INGECTH-SUS STUDY}

doi:10.1136/jech.2011.142976p.91

${ }^{1} \mathrm{M}$ Y Mauro, ${ }^{2} \mathrm{R}$ Guimarães, ${ }^{*} \mathrm{~L}$ Santiago, ${ }^{4} \mathrm{C}$ Mauro. ${ }^{1}$ University of State of Rio de Janeiro, Rio de Janeiro, Brazil: ${ }^{2}$ Federal University of Rio de Janeiro, Institute of Studies in Public Health, Rio de Janeiro, Brazil; ${ }^{3}$ Oswaldo Cruz Foundation, Rio de Janeiro, Brazil; ${ }^{4}$ MI2 Ergonomics, Rio de Janeiro, Brazil

The goal of this study is to present the reliability test of Boix and Vogel's risk assessment scale in work environments for health area in Brazil. For this, 73 nursing professionals from Brazil answered the scale version, and replied the instrument with a range of 15 days. For internal consistency evaluation of dimensions it was used the Cronbach's $\alpha$; to assess the strength of association between the constructs was used the intraclass correlation coefficient (ICC); and to evaluate the consistency of response in two times interview was used the weighted $\kappa$. The ICC showed excellent correlation between dimensions, ranging from 0.87 and 0.96 . About internal dimensions consistency, Cronbach's $\alpha$ values varied from 0.64 to 0.85 . On the items, the weighted $\kappa$ varied from 0.66 (95\% CI 0.52 to 0.81 , and 0.93 ( $95 \%$ CI 0.87 to 0.99 ). The results of this study indicate that the scale shows high reproducibility for all dimensions evaluated.

\section{SP6-21 PATTERNS OF BREASTFEEDING AND DETERMINANT FACTORS IN BRAZIL}

doi:10.1136/jech.2011.142976p.92

${ }^{1} \mathrm{P}$ Pinto, ${ }^{2} \mathrm{R}$ Guimarães, ${ }^{*}{ }^{3} \mathrm{~L}$ Rangel, ${ }^{4} \mathrm{M}$ Ribeiro. ${ }^{1}$ Gaffrée Guinle University Hospital, Rio de Janeiro, Brazil; ${ }^{2}$ Federal University of Rio de Janeiro, Institute of Studies in Public Health, Rio de Janeiro, Brazil; ${ }^{3}$ Rio de Janeiro University, Rio de Janeiro, Brazil; ${ }^{4}$ Federal University of Rio de Janeiro, Rio de Janeiro, Brazil

Breastfeeding has innumerable advantages on the child, its family and society. Although the governmental efforts, of the professionals of health and the society in the direction to promote, to protect and to support this practical, the prevalence of exclusive breastfeeding until 6th life month remains less than ideal. The objective of this study is to determine the correlation of exclusive and non-exclusive breastfeeding with some basic health indicators, supplying data that they may be able to help for the development of interventions that include breast-feeding overall its conjuncture. An ecological study has been carried through using secondary data from DATASUS will be, from the period of 1999 to 2000's. The correlation has been esteemed through Pearson's coefficient. Is was observed a statistically significant correlation to variables related to marital status, education, coverage of prenatal, delivery characteristics and infant mortality rate after neonatal and proportional for IPD. It is observed therefore that the actions, especially in prenatal and multiplepatient room, must be prioritised in these groups which showed an inverse correlation.

\section{SP6-22 STUDY OF INFRASTRUCTURE AND MANPOWER OF PHCS AND SUB-CENTRES IN NELLORE DISTRICT, ANDHRAPRADESH, INDIA}

doi:10.1136/jech.2011.142976p.93

S Sriram, ${ }^{*}$ V Chandrasekhar. Narayana Medical College, Nellore, Andhrapradesh, India

India has a vast public health infrastructure in the country with 23391 primary health centres and 145894 sub-centres providing health services to $72.2 \%$ of the country's population living in rural areas. Although the numbers look impressive their functional status needs to be improved in terms of physical infrastructure, manpower, equipment, drugs and other logistic supply that are very much needed for ensuring quality services. National Rural Health Mission (NRHM) launched aims to restructure the delivery mechanism for health towards providing universal access to equitable, affordable and quality healthcare, as a result of which Indian Public Health Standards (IPHS) were formulated. The present work aims to study the infrastructure facilities and manpower in a sample of Primary Health Centres (PHCs) and their subcentres in the district of Nellore in the state of Andhra Pradesh in the east coast of India. A randomly selected sample of health institutions have been studied using structured and pre-tested performance. The data have been analysed with reference to Indian Public Health Standards (IPHS). It is a cross-sectional community based study done over a period of 1 year in Nellore district in the study setting of primary health centres and sub-centres. There are 62 primary health centres in Nellore district distributed in three divisions (Gudur, Nellore and Kavali). 25\% of the primary health centres have been selected randomly that is, 15 PHCs taking five from each division randomly. Each PHC consists of 